\title{
Application of Steel Fiber in Increasing the Strength, Life-Period and Reducing Overall Cost of Road Construction (by Minimizing the Thickness of Pavement)
}

\author{
Abdul Ahad, Zishan Raza Khan, Shumank Deep Srivastava \\ Department of Civil Engineering, Integral University, Lucknow, India \\ Email: Abdulahad48471@gmail.com, Aahad@iul.ac.in, zishanrk@iul.ac.in, shumank2012@gmail.com, \\ Shumank@iul.ac.in
}

Received 21 September 2015; accepted 16 November 2015; published 19 November 2015

Copyright (C) 2015 by authors and Scientific Research Publishing Inc.

This work is licensed under the Creative Commons Attribution International License (CC BY). http://creativecommons.org/licenses/by/4.0/

(c) (i) Open Access

\section{Abstract}

Recently, the use of steel fiber at high rates has been introduced as the sole method of reinforcement for fully elevated-suspended slabs having long span such as $5 \mathrm{~m}$ to $8 \mathrm{~m}$ each way, with a span to depth ratio of up to 33 [1]. As a result of long practical experience the total replacement of traditional rebar is a new routine. Now it is also used in the designing of SFRC pavements over conventional concrete pavements. Within the project framework a demonstration of a steel-fiberreinforced roller-compacted concrete (SFR-RCC) pavement was constructed in a rural as well as urban area. In order to assess the economical condition of the demonstration pavement, life cycle assessment (LCA) and life cycle cost analysis (LCCA) studies were undertaken. This is the advancement study of the various papers which is already published in many publications which serve as the main and important source of study for the research. Many applications of steel fiber are listed in the paper but the main output of this paper is that SFR-RCC is more economically sustainable than others and also helps in reducing the thickness of the pavement up to 20 to 25 percent, due to the excessive strength of steel fiber. The roads of the present system required high cost investment. And the life period is almost 20 years theoretically but the actual life of the road is depending on the maintenance and the applied load. The constructions of road have been done since the $3500 \mathrm{BC}$ but the method does not change fully. Also the cost of the construction is increased continuously; as a result, the construction of roads is more and more complicated and time taken. For the better and economical construction of the roads, we use steel fibers in the composite pavement. The theoretical plan of the construction of composite pavement is given in the methodology, which gives the appropriate idea about the construction of road using steel fiber. Here we use the composite pavement in which the steel fiber is mixed in the concrete layer, after which the bitumen layer is laid for the smooth and suitable riding of the vehicles. 


\section{Keywords}

\section{Steel Fiber Reinforced Concrete (SFRC) Roads, History of Roads, Life Cycle Assessment (LCA), Life Cycle Cost Analysis (LCCA), Concrete Reinforcement, Economical Road}

\section{Motivations}

The generation of idea that concrete could be strengthened by fiber was first put forward by Porter in 1910, but little progress was made in its development till 1963, when Roumaldi and Batson carried out extensive investigations and published their classical paper on the subject. Since then, there has been a great wave of interest in and applications of SFRC in many parts of the world [2].

In Australia, the steel fiber shown in Figure 1 is used maximally, due to many years at very high percentage [3]. The steel-fiber-reinforced concrete (SFRC) in Australia has been growing 30 to 40 percent per year. Since an Australian manufacturer introduced enlarged-end steel fibers to the country in 1975, more than 30 ready mixed concrete companies have supplied SFRC. The material has been batched by more than 200 batch plants, both large automated city plants and small portable plants. It is now included in Australia's Swimming Pool Standard (AS2785) and its Septic Tank Standard (AS1546). Its inclusion in Australia's Concrete Structures Code (BD2) is also being considered now.

After many studies about the use of steel fiber, the idea is coming into existence about the use of the steel fiber in the composite pavement construction of road to enhance the strength and workability of road. In conclusion, due to the excessive strength of steel fiber, pavement thickness can be reduced up to 20 to 25 percent and it is also added to the concrete to provide toughness in the hardened state for reducing the failure of cracking due to long term drying, shrinkage, load and fatigue.

\section{Introduction}

The motive of the research and studies is that the SFRC Roads is more economically sustainable than others.

Before understanding the benefits and results of the use of steel fiber in roads, first we study about the history of roads with the present condition of road for understanding the economical use of steel fiber in composite pavement of roads construction.

\section{History of Roads}

In the ancient times, it was nothing more than a scanty network of roads (tracks) for humans to use in order to reach his basic requirement like feeding and drinking places. These tracks are used not only by humans but also by animals. But many obstacles like boulders and thorn bushes were removed from the more important routes by humans only [4].

More roads communication than these simple tracks did not appear until the increasing number of people in that specific areas and the social structure and organization of communities demanded more permanent contact between communities.

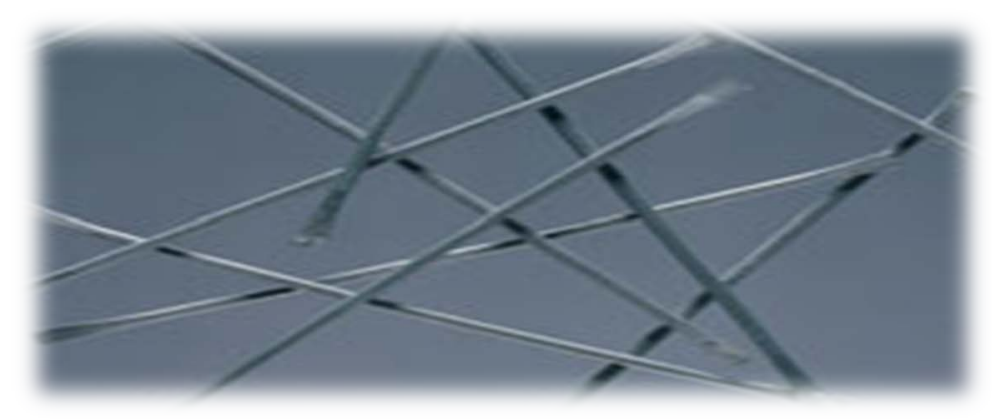

Figure 1. Steel fibers. 
Roads appeared when groups of people started to interact with each other for travelling, fighting, or for business. This occurred around $3500 \mathrm{BC}$ with the invention of the wheel and development of chariots and wagons.

The earliest records of paved roads for wheeled traffic dated about $2200 \mathrm{BC}$ in Babylonia (modern Iraq), in Crete about 1500 BC and in Egypt about 540 BC.

In Europe the first substantial roads were built by the Romans (a network of more than $100000 \mathrm{~km}$ 's of road was built between $400 \mathrm{BC}$ and $400 \mathrm{AD}$ ). The Roman roads were cambered to shed rainwater and were constructed on a foundation of large stones with a wearing course of smaller stones and gravel. The Romans were the best road builders which help in achieving conquests through war.

It also helps Romans to control their conquered subjected nations as good network of roads. The army needed to be able to move fast in order to quell any revolting groups.

They developed a 3/4 layer system of:

- Top layer;

- Base/sub-base layer (sometimes with a stabilized material in the base);

- Sub-grade.

After the collapsed of Roman Empire, the structure roads began to degenerate.

In the late $18^{\text {th }}$ and early $19^{\text {th }}$ centuries, Napoleon was responsible for the construction of a network of roads in Europe.

Further, in 1765, Tresaguet developed the Roman road structure. His basic principle was to construct the first layer with big blocks and then to place little rocks in between. By this, he attempted to ensure that the first layer was consistently exposed to compressive stresses, by which it achieved better load spreading on the sub grade.

In the mean time, in England, many constructors such as Telford and Metcalf made valuable developments, such as:

- Design of drainage;

- Design of the road camber;

- Active and regular maintenance.

In Great Britain, the Industrial Revolution required a road building program to satisfy the need for the movement of materials and goods, thus many kilometers of road were built by various means.

During this time, John Macadam invented a method of road building as follows:

After careful preparation and draining of the roadbed, he laid a $25 \mathrm{~cm}$ layer of stone followed by a surfacing of smaller stones. This type of roadway was ideal for animal drawn wagons and coaches, and was cheap to build. John Macadam's roads were a good solution in the nineteenth century for iron rims i.e. treads.

However, the invention of motorised transport and rubber tires changed the requirements once again. A speed increased with safety is an important consideration now. Rubber wheels "sucked" the dust from the road surface, loosening the stones and causing blinding clouds of dust. So, in the early part of the 20th century, "tar" was spread over the entire road surface to hold the stones at its definite place and to prevent dust. Sand and stone with tar formed a "surface dressing". Today, we still make water-bound macadam (W.B.M) and penetration macadam.

In South Africa the pioneer road-builder was Thomas Charles Bain. Thomas Bain constructed 23 major mountain roads, nearly all in the Cape Province. Some of his roads are still in using today.

In 1863, the invention of two-wheel steamroller and three-wheel steamroller made compaction of granular layers comparably easier and the quality of compaction increased.

Till early 1920's the thickness of pavements was based purely on experience. The invention of the cars gave a strong impulse to look at design of roads more seriously. The friction between tyre of the cars and road causes damage to the surface and unpaved roads could not cater for this. So the result, the design norms revised and considered new following rules in the $20^{\text {th }}$ century:

- Empirical design systems i.e. experience- and observation-based designs;

- Mechanistic design systems (linking performance to pavement properties and failure mechanism);

- Empirical-mechanistic design systems.

In the $20^{\text {th }}$ century, the car is one of the main modes of the transport. After the Second World War, growth in traffic on roads, tyre pressures and higher speeds shows the necessary development of pavement technology beyond empiricism or designs based on experience only. Functional performance had to be defined, being the basis of the service that is provided to the road users in relation to the cost. Performance also needed to be better 
understood and predictable. This required knowledge of structural behavior and pavement distress in relation to time. This motivated the AASHO road test.

- AASHO stands for "American Association of State Highway Officials" and later became AASHTO;

- It was an enormous effort to systematically quantify the complex interaction between road deterioration, traffic and composition of the pavement structure on a closed loop test track with trucks;

- The aims of the AASHO road test are still very relevant:

- Developing satisfactory pavement design procedures to meet the growing demands of traffic;

- Aid legislators in setting user taxation and control of vehicle size and weight.

For the first time the relationship between performance and loading was investigated.

The two main findings were:

- Present Serviceability Index (PSI): The test was the first in which many faces of pavement condition and its progressive change with time (deterioration) were defined and quantified. The PSI was statistically related to roughness, rutting and cracking by the subjective PSR determined from users of the road.

- Load equivalency: The load equivalency factor relates the number of load repetitions of a given axle load to the equivalent number of $80 \mathrm{kN}$ loads. It can be used for comparing the damaging effect of different loads.

In the modern world it is well known that apart from social factors such as transport to visiting friends and tourism, quick access to a fire and emergencies, hospitals, a good road system is the backbone for all kinds of economic activity.

John F Kennedy is well said:

"It is not America's strong economy that gave us our good roads,

But rather our good roads that gave us our strong economy!"

The Land Registration was started in the 1960s ensured that each farmer should have a road access.

It ensures that the farmer could reach his farm with commodities such as tree seedlings, building blocks and fertilizer. It also meant that the farm produce, in the form of bags of maize or coffee, could be got out to the markets or for processing at the factory.

Construction of rural roads is only one aspect to pavement engineering. Another aspect is maintenance. All roads have to be cared for and without this maintenance lose their intrinsic value.

In order to fund new road construction, developing countries often take out loans from institutions such as be backed up with a parallel loan for repairs to existing roads. Roads are important assets to a country and need a maintenance program to ensure that the longest life is achieved. In developing countries, initiatives such as local community programs for filling potholes in return for donations deserve to be taken more seriously.

\section{Types of Pavements}

Road Pavements can be divided into 3 major types [5]:

a) Flexible pavements (upper layers of Asphalt);

b) Rigid pavements (upper layers of Concrete);

c) Composite pavements.

a) Flexible Pavements:

Flexible pavements consist of six layers with their approximate thickness of layer:

1) Surface course $(2-5 \mathrm{~cm})$;

2) Binder course $(5-10 \mathrm{~cm})$;

3) Base course $(10-30 \mathrm{~cm})$;

4) Sub-Base course $(10-30 \mathrm{~cm})$;

5) Compacted sub-grade $(15 \mathrm{~cm})$;

6) Natural sub-grade.

This pavement structure is quite popular in areas where local materials are not available i.e. limited base and sub-base aggregates available in the area.

Advantages of Asphalt pavements can be:

a) They do not have permeable layers that entrap water (such as granular layers);

b) Time required for construction is relatively low. Beneficial on widening the projects where traffic flow must be accommodate;

c) When placed in thick layers, the construction season is not very limited; 
d) Asphalt pavements provide and retain uniformity in the pavement;

e) It seems that the moisture contents do not build up in sub grades under these types of pavement structures, causing little or insignificant reduction in sub grade strength.

\section{b) Rigid Pavements:}

Rigid pavement has six numbers of layers are shown in Figure 2.

The rigid pavement is constructed by using the concrete and reinforcement. This type of pavement is more strength than flexible pavement. It is also economical.

There are different types of concrete pavements:

1) Jointed plain concrete;

2) Jointed reinforced concrete;

3) Continuously reinforced concrete;

4) Pre-stressed concrete

\section{c) Composite Pavements:}

The components of both flexible and rigid pavements are combined in one road structure, for construction of composite pavements. Example of a composite pavement is a concrete pavement where the concrete surfacing layer is supported by an Asphalt layer. Characteristics of composite pavement are as shown in Figure 3.

\section{Causes for the Use of Steel Fiber in the Composite Pavement Construction and Its Properties}

- One of the important properties of SFRC is its superior resistance to cracking and crack propagation. Because of this ability, the fiber composites possess increased extensibility and tensile strength, both at the initial crack to ultimate crack, and the fibers are able to hold the matrix together even after extensive cracking as shown in Figure 4. The net result of all these is to impart to the fiber composition for cracking, ductility which is unheard in ordinary concrete. The transformation from a brittle to a ductile type of material would increase substantially the energy absorption characteristics of the fiber composite and its ability to withstand repeatedly applied, shock or impact loading.

- Due to its excellent resistance to impact and abrasion, SFRC originally was also used for heavy-duty floors and pavements in many developed countries like American, Australian. A lot of SFRC used for flooring, in many industries like coal and ore mining industries as wash-down pads, and load standing areas. It may also used slip-formed slabs under railway tracks and for pavements in heavy-duty factory, container handling areas, bus parking lanes, floors.

- Due to containing fewer fibers, its cost less, making them economical for many other uses. Now they also are used for warehouse floors, tennis courts, and some residential floors. Though they aren't used much in highway construction, they are used for roads with light to medium traffic, typically at 10 to $12 \mathrm{~cm}$ thicknesses.

- No special dispensing equipment is required for mixing of steel fibers. Contractors can finish the concrete with standard concrete equipment. This makes it faster and so easier to place than concrete reinforced with

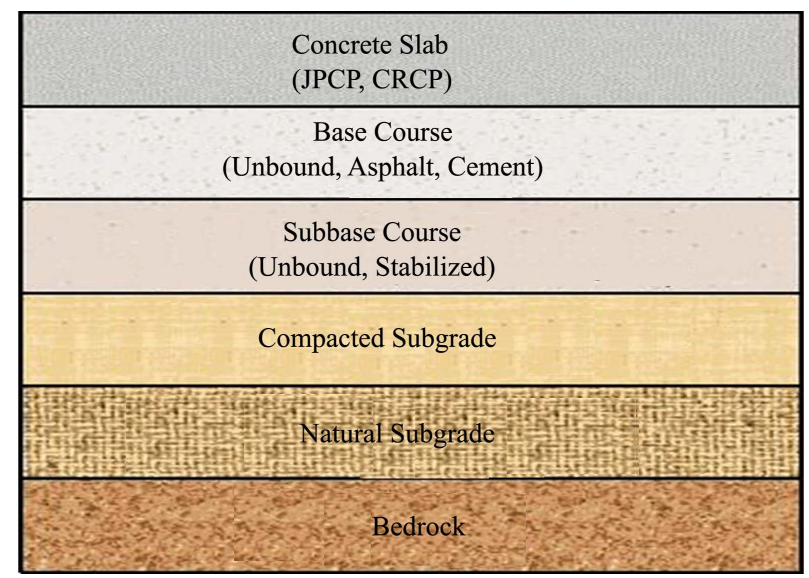

Figure 2. A typical cross-section of a rigid pavement layers. 
mesh or rebar.

- It's also having comparative low cost with concrete reinforced with mesh or rebar [6].

Because of these qualities, steel fibers were developed in three standard mixes for:
a) Heavy-duty;
b) Light-duty;
c) Residential uses.

\section{Methodology for the Use of Steel Fiber in the Pavement}

As we discussed above, about the pavement and their ability on different situation,

The principles of sound pavement design systems can be used for any type of structure with its specific requirements.

Some examples are:

- Industrial areas;

- Harbors;

- Runways, taxi ways, aprons at airports;

- Railways;

- Dykes, etc.

The principles remain the same, but the loads of given example are totally different from normal pavement loading. For example, industrial areas may have static loads of containers stacked upon each other than the load of the vehicles on the normal roads.

To overcome these different loading on a normal roads or the specific roads, it must have to increase the tensile strength of pavement, but in an economical way.

The solution is the construction of "Composite Pavement" with the use of steel fibers.

The reason of the use of "Composite Pavement" instead of the use of rigid pavement as well as flexible pavement only is that the Composite pavement consist both the type and are also bothered the properties of both. For the analysis, Layers are shown in Figure 4 and Figure 5 clearly.

Flexible pavement does not hold the good rigidity on the running surface. When the wheel loads apply on it, it does not resist properly and the small (or micro) cracks are developed in it, but it contains the good surface finish with providing a smooth riding surface.

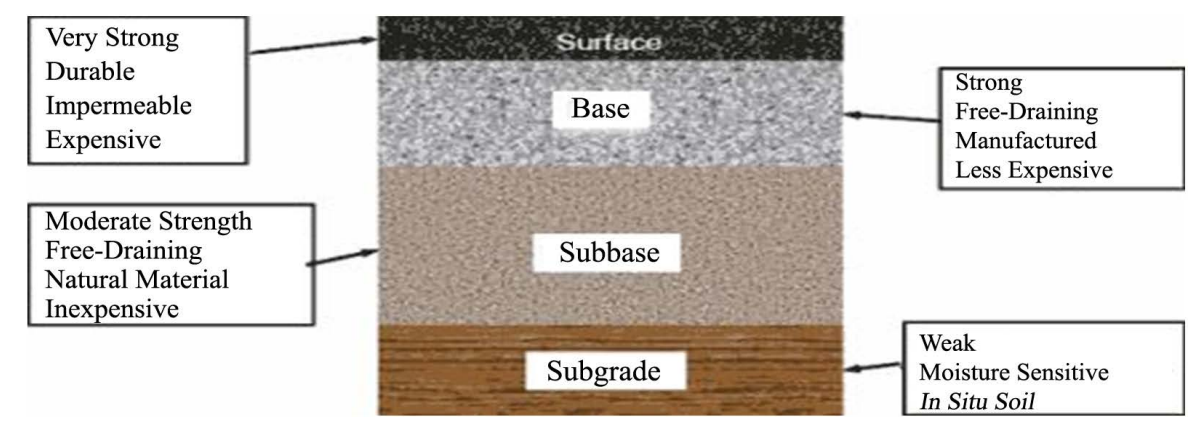

Figure 3. Cross section of composite pavement.

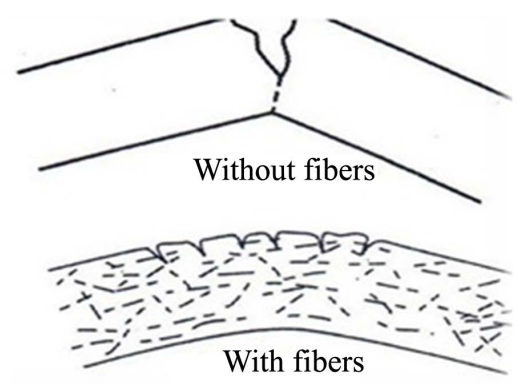

Figure 4. Failure mechanism of pavement and the "effect of fibers". 
While, the rigid pavement contains good strength and resistance against the wheel-load, but it has rough surface for the riding of wheel. It also heat up the rubber of the tyre, due to which large accident occurs.

So, on conclusion, the composite pavement gives the better result for the analysis. In which Concrete as well as Asphalt layers are used. From Figure 5, the bitumen is used on the Top layer for the good surface finish. After that, the Bitumen Stabilized Base layer provided for the compaction of the load.

The intermediate layer is not important, when steel fibers are used. This layer is reduces, due to which the cost of road construction is also reduces.

After the second layer of the composite pavement, the concrete layer is laid, in which the steel fibers are mixed.

The R.C. Concrete is most widely used structural component in which cement is the material which is highly used in the world with an annual production of over Ten billion tons. Concrete is a composite material containing hydraulic cement, water, coarse aggregate and fine aggregate. The resulting material is a stone like structure which is formed by the chemical reaction of the cement and water. This stone like material is a brittle material which is strong in compression but very weak in tension. Many times the cracks may be attributed to structural, environmental or economic factors. But the main reason for concrete to suffer cracking when heavy wheel-load are apply on it, in mostly cases, are formed due to the inherent weakness of the material to resist tensile forces. Again, concrete shrinks and will again crack, when it is restrained. The tensile strength of concrete is less due to widening of micro cracks existing in concrete subjected to tensile stress.

Due to which, Steel fiber is taken as a solution to develop concrete in view of enhancing its tensile strength.

Over the past 4 decades, a number of studies have demonstrated the technical merits of Steel fiber reinforced concrete (SFRC). The new trend of using this technique completely replaces all traditional rebar and mesh. Because of excessive strength due to steel fiber, pavement thickness can be reduced up to 20 to 25 percent.

The design method is used which is outlined in the code of practice of Bureau of Indian Standards, New Delhi, India [7]-[10]. In addition, the consideration of the strength of steel fiber and also the consideration should be given to the requirement for durability, ductility and fire resistance. Also important considerations are suitable fiber and materials, with workmanship and quality control.

Unreinforced, Plain concrete is a brittle material, with a low tensile strength and strain capacity; it is easily break but the concrete with fiber posses' high tensile strength, shown in Figure 4. The discontinuous randomly distributes steel fibers is to bridge across the cracks where it develop, and also provides some "Post-cracking ductility". If the fibers are sufficiently bonded to material, and permit the SFRC to carry significant stresses over a relatively large strain capacity in the post-cracking stage. There are probably cheaper ways of increasing the strength of concrete. The main focus on the fibers is to increase the toughness of the concrete under any type of loading.

The different type of loads which discussed above, developed the stress on the concrete, due to which the roads cracks from different places in normal conditions but by using the steel fibers, this load is distributed on the entire length of pavement which is absorb by the steel fibers without any cracking of road. This process enhanced the life of the roads by resisting the veir and tier of the pavement of road.

The matrix of concrete, mixes with steel fibers, are uniformly distributed across its entire mass on pavement and gets strengthened enormously, thereby rendering the matrix to behave as a composite material with properties comparatively different from conventional mixer of concrete and Bitumen. The fiber is used randomly distribution of fibers throughout the area of construction with the advantages of the fiber is to shear resistance and crack control.

The randomly-oriented steel fibers assist in controlling the propagation of micro-cracks present in the mixer, initially by improving the overall cracking resistance of matrix itself, and then by bridging across even through smaller cracks formed after the application of load on road, and also preventing their widening into major cracks.

When the steel fiber is in small size or potable size, they act effectively as rigid component in the concrete matrix. Due to the inherent properties of fiber concrete, the presence of fibers in the body of the concrete or provision of a tensile SFC can be expected to improve the resistance in the members to wear and tear, internal cracks, deflection and other serviceability conditions. The strength of road increases depending upon the variable quantity of steel fiber in the pavement. 
The steel fiber is enough strong that to allow the strength of the fiber to be developed along the entire length of the fiber. The SFR pulls through to prevent the fiber breakage or brittle failure that reaches ultimate strength of the steel fiber.

First we prepare layers such as sub-Base, Base, and the purposed layer of concrete mix with the steel fibers, as shown in Figure 6. The formation of the layers of the road is given as:

After which the Bitumen layer are laid for the smooth surface of the road. This all process prepare the composite layer of steel fibers, which gives the strength, durability as well as reduces the cost of construction of road.

The final road of composite pavement with steel fiber or SFRC is likely as Figure 7.

The summary of using the steel fiber with the benefits and features in road pavement is shown in Table 1.
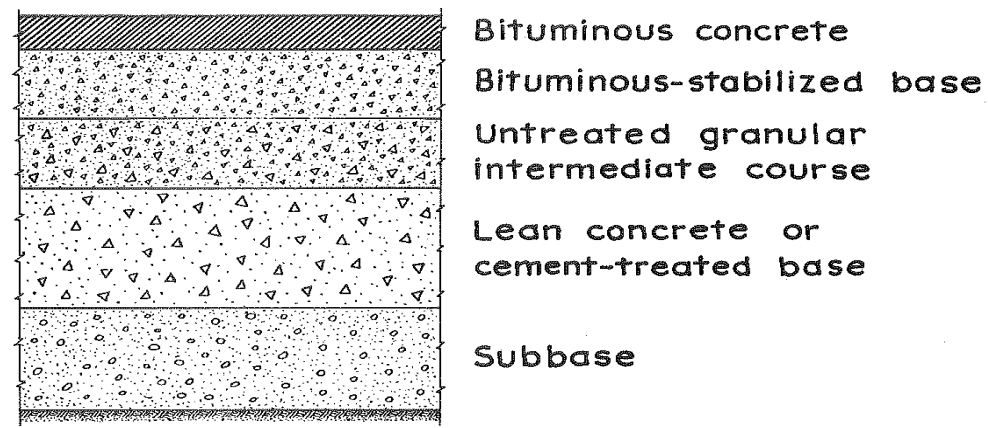

Figure 5. Composite pavement.

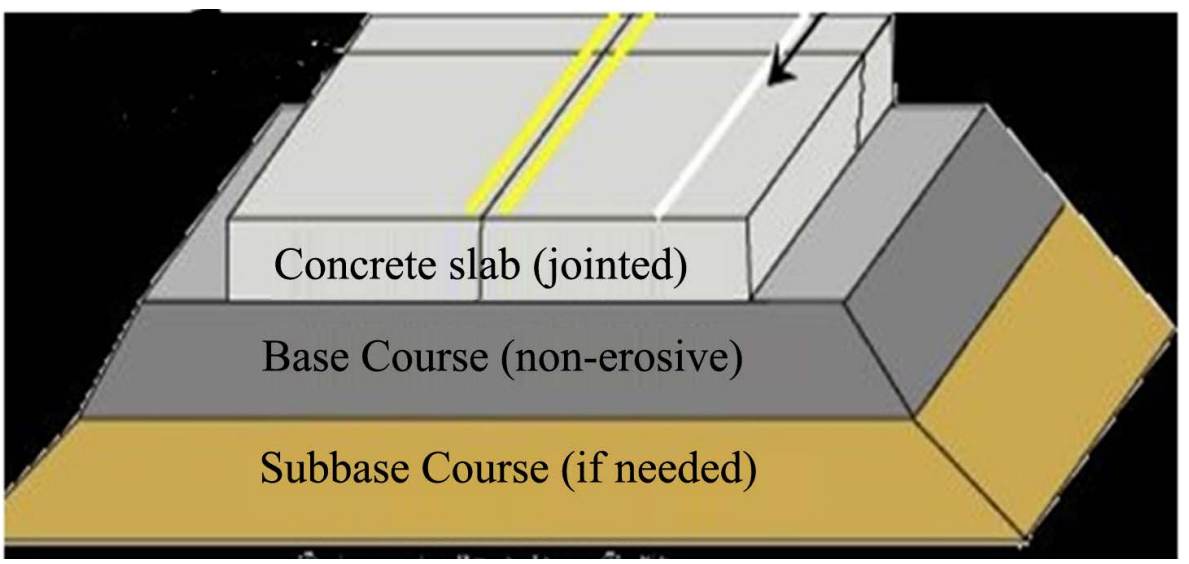

Figure 6. Rigid pavement like structure.

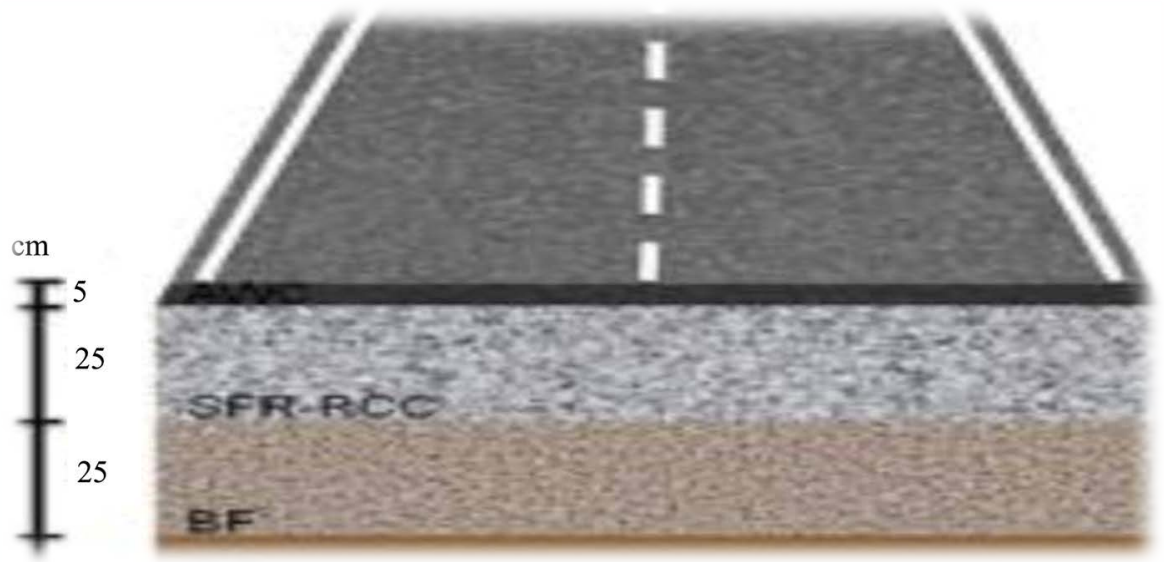

Figure 7. Composite pavement with steel fiber or SFRC. 
Table 1. Summary of using steel fiber in roads construction.

\begin{tabular}{cc}
\hline Features & Benefits \\
\hline Increases flexural toughness/residual strength. & $\begin{array}{c}\text { Increased load bearing capacity of concrete. } \\
\text { Potential reduction of concrete slab depth. }\end{array}$ \\
Provides post-crack performance & $\begin{array}{c}\text { Concrete retains load carrying capability after cracking has occurred. } \\
\text { Increased abrasion and impact resistance. }\end{array}$ \\
\hline
\end{tabular}

\section{Design of SFRC for Matrix Formation}

Depending upon the requirements for the construction purpose such as workability, strength, etc., the mix of SFRC varies in different proportions. Several procedures for proportioning SFRC mixes are available, which enhance the workability of the resulting mix. However, there are some considerations are given that particular to SFRC [11].

In general, SFRC mixes contain higher ratios of fine to coarse aggregate and higher cement contents than comparing to ordinary concretes, and so the mix design procedures the apply to conventional concrete may not be entirely applicable to SFRC. In addition, to improve the workability of higher fiber volume mixes, water reducing admixtures.

From the data of estimated traffic volume on the site of construction from different methods and grade characteristics, for evaluating the sub-layer thickness of composite pavement, the tensile strength of the concrete and asphalt is the key factor for construction, by which estimation result shows the steel fiber reinforcement consumption with the increment in the tensile strength of concrete. Also the steel fibers are enough strong that it allows the strength of the fiber to be developed along the entire length of the fiber and the SFR binds tightly that to prevent the fiber breakage or brittle failure that reaches ultimate strength of the steel fiber. The use of fiber Reinforced concrete for the construction of road is one of the most important ways to reduce material consumption [12]. An example of mix having steel fiber is shown in Figure 8.

A particular fiber type, orientation and percentage of fibers, the workability of the mix decreased as the size and quantity of aggregate particles greater than $5 \mathrm{~mm}$ increased; the presence of aggregate particles less than 10 $\mathrm{mm}$ in diameter had little effect on the compacting characteristics of the mix [13].

The second factor which has a major effect on workability is the aspect ratio (1/d) of the fibers. The workability decreases with increasing aspect ratio.

\section{SFRC Specifications and Precaution for Using Composite Pavement}

When SFRC is used in matrix, the following clauses shall be included in specification [14]. These are as follows:

- The steel fibers are to be made from hard and low carbon steel, in such a way, that it should have a tensile strength greater than $1000 \mathrm{MPa}$ [15].

- The steel fibers are properly mixed with the concrete, aggregate mix and settle in the layer that to overcome the problem of tier of pavement by which the accident occur.

- The fibers shall be properly checked in such a way that the risk of cracking is eliminated.

- The steel fibers are distributed properly over an entire surface of the pavement, for the uniform distribution

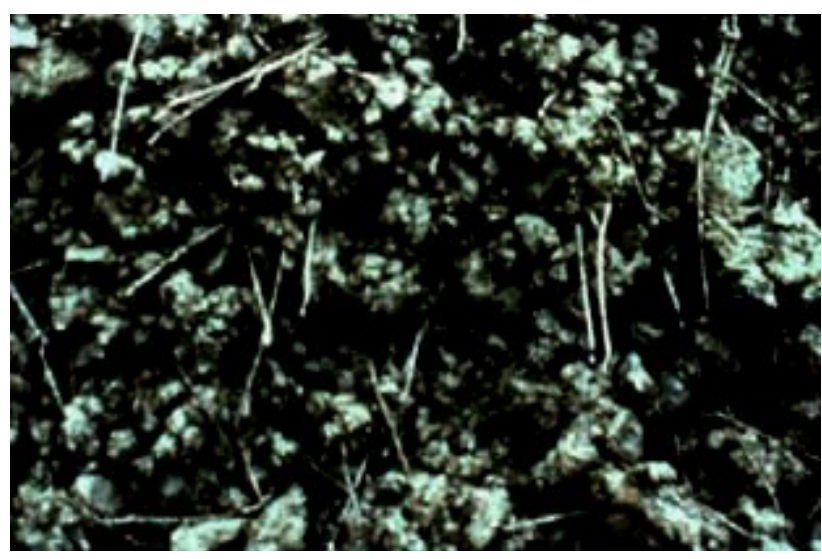

Figure 8. Mix of aggregate and steel fiber. 
of the load on the pavement.

- To ensure adequate overlap between fibers to carry the load continuously through the element.

- Proper installation and settlement of Steel fibers are done that it is also added to the concrete for providing the toughness in the hardened state for reducing the failure of cracking due to long term drying, shrinkage, load and fatigue.

\section{Advantages of Steel Fiber over Mesh}

- Saves the cost of placing mesh

- Excellent surface finish by using a low dosage of the highest performance fiber.

- The steel fiber is enough strong that to allow the strength of the fiber to be developed along the entire length of the fiber.

- Eliminates sapling of concrete due to steel corrosion.

- Fiber reinforcement is supplied in concrete by Firth; using quality assured mixes and materials.

- Eliminates concern that mesh may not be placed at the right location in the pavement.

- Increases construction speed.

- Reduces edge and joint damage.

- The SFR binds and pulls through to prevent the fiber breakage or brittle failure that reaches ultimate strength of the steel fiber [16] [17].

\section{Technical Advantages}

It Support related to most aspects of the use of SFRC in construction of road pavement. These supports are in the following way:-

- By the use of steel fiber, it support the Government as the client (investor) with the Designer, Engineer and Contractor in term to develop a cost effective and appropriate technically High Performance Concrete solution that gives effectively advantages to all parties [18].

- Guidance on the placing of Steel fiber to provide a high quality finish.

\section{Main Advantages of Steel Fiber in Using Road Construction}
A) Reduced construction time: The time will be reduced 5 to 10 percent;
B) Reduced thickness;
C) Reduced overall cost;
D) Impact crack control;
E) Simplified job site operation;
F) Good impact resistance;
G) Improved ductile behavior.

\section{Other Applications of Steel Fibers}

SFRC is used as a construction material in various fields and has been extensively used for many applications:

- Free suspended industrial slabs resting on a grid of piles where the ground does not provide sufficient bearing capacity;

- Heavy duty flooring applications - internal \& external;

- Steel fiber reinforced tunnels;

- Used in suspension bridge's pillars or piles;

- Ground bearing rafts for foundations under tanks, apartments, shopping malls or office blocks;

- Shallow footings;

- Composite metal decking and bridge slab applications;

- Joint-less floors;

- Helpful in resisting Earthquake.

\section{Conclusions}

From the above study about the "use of steel fiber in the construction of roads", it can be concluded that the use 
of steel fibers is economical as well as effective in increasing the strength of pavement. It is one of the good alternative solutions to the modern transportation system of developing countries like India. By the use of steel fibers, the thickness of road reduces up to $25 \%$ to $30 \%$ with the increase in the durability of the road pavement, so it can decreases the Overall cost of the road construction. The different type of loads is easily movable without the construction of any special type of pavement. It is totally favorable to the Government of the specific country in the economical investment on the roads. And it is also helpful to reduce the material consumption on the construction of roads.

Because of reducing the concrete or material usage, the ill effect of cement usage reduces on the environment. It also posses high strength, so it has long durability. The construction is fast and time consuming is less, so it is also efficient in working ability.

Overall conclusion from above entire paper is that the use of steel fibers in the road construction is economical and eco-friendly. The final composite pavement or SFRC is shown in Figure 8.

\section{References}

[1] Japan Concrete Institute (1983) JCI Standards for Test Methods of Fiber Reinforced Concrete. Method of Test for Flexural Strength and Flexural Toughness of Fiber Reinforced Concrete (Standard SF4), 45-51.

[2] Craig, R.J. (1984) Structural Applications of Reinforced Steel Fibrous Concrete. Concrete Int. Design and Construction.

[3] Uses for steel-fiber-reinforced concrete in Australia". An article of "The Aberdeen Group" which is based on the Australian paper "The Diversifying Applications of Steel Fiber Reinforced Concrete in Australia" by "Winston A. Marsden", Technical Development Manager of AWI Fiber steel, Australia.

[4] http://HistoryofRoadPavement.com

[5] Jenkins, K. Introduction to Road Pavements. In: Hitchhiker's Guide to Pavement Engineering.

[6] ASTM C1018-89 (1991) Standard Test Method for Flexural Toughness and First Crack Strength of Fiber Reinforced Concrete (Using Beam with Third-Point Loading), Book of ASTM Standards, Part 04.02. American Society for Testing and Materials, Philadelphia, 507-513.

[7] IS-383 (1970) Specification for Coarse and Fine Aggregates from Natural Sources for Concrete. 2nd Revision, Bureau of Indians Standards, New Delhi.

[8] IS-10262 (2009) Recommended Guidelines for Concrete Mix Design. Bureau of Indian Standards, New Delhi.

[9] IS-456 (2000) Indian Standard Code of Practice for Plain and Reinforced Concrete. Bureau of Indian Standards, New Delhi.

[10] IS-800 (2007) Indian Standard Code of Practice for Steel. 3rd Revision, Bureau of Indian Standards, New Delhi

[11] Chand, N.V. Steel Fiber Reinforced Concrete. Vietnam Joint Seminar.

[12] Balaguru, P.N. and Shah, S.P. (1992) Fiber Reinforced Cement Composites. Mc Graw Hill International Editions.

[13] Sinha, D.A. Characteristics Properties of Steel Fiber Reinforced Concrete with Varying Percentages of Fiber.

[14] Johnston, C.D. (1974) Steel Fiber Reinforced Mortar and Concrete. A Review of Mechanical Properties in Fiber Reinforced Concrete ACI-SP 44-Detroit.

[15] Barros, J.A.O. (2002) Flexural Behavior of Steel Fiber Reinforced Concrete. Testing \& Modeling.

[16] ACI Committee (1982) State of the Art Report in Fiber Reinforced Concrete. ACI 554 IR-82 Detroit Mechigan.

[17] Henager, C.H. (1981) Steel Fibrous Shotcrete. A Summary of the State-of-the Art Concrete Int.: Design and Construction.

[18] Endgington, J., Hannant, D.J. and Williams, R.I.T. (1974) Steel Fiber Reinforced Concrete. Current Paper CP 69/74 Building Research Establishment Garston Watford. 